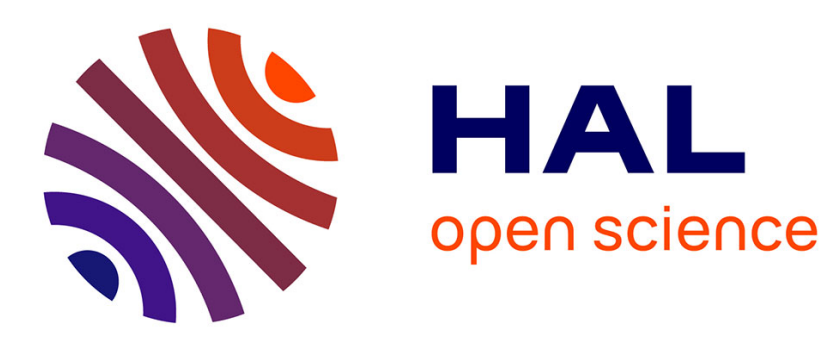

\title{
In-situ scanning tunneling microscopy of the semiconductor-electrolyte interface \\ Philippe Allongue
}

\section{To cite this version:}

Philippe Allongue. In-situ scanning tunneling microscopy of the semiconductor-electrolyte interface. Journal de Physique IV Proceedings, 1994, 04 (C1), pp.C1-323-C1-327. 10.1051/jp4:1994125 . jpa00252467

\section{HAL Id: jpa-00252467 https://hal.science/jpa-00252467}

Submitted on 1 Jan 1994

HAL is a multi-disciplinary open access archive for the deposit and dissemination of scientific research documents, whether they are published or not. The documents may come from teaching and research institutions in France or abroad, or from public or private research centers.
L'archive ouverte pluridisciplinaire HAL, est destinée au dépôt et à la diffusion de documents scientifiques de niveau recherche, publiés ou non, émanant des établissements d'enseignement et de recherche français ou étrangers, des laboratoires publics ou privés. 


\title{
In-situ scanning tunneling microscopy of the semiconductor-electrolyte interface
}

\author{
P. ALLONGUE
}

UPR 15 du CNRS, Université P. \& M. Curie, 4 Place Jussieu, Tour 22, 75005 Paris, France

\begin{abstract}
:
The great reactivity of semiconductor surfaces and the easy formation of oxide layers make in-situ STM imaging of the semiconductors/electrolyte interface difficult at a high resolution. Additionally, STM imaging of such interfaces requires some care as far tunneling conditions are concerned. The paper analyses this question with the system $\mathrm{Si} / \mathrm{NaOH}$ to illustrate the latest advances concerning in-situ imaging of the semiconductor electrodes. The etching of the (111) face has been studied at an atomic level over a wide range of potentials and the effect of species added into the solution (to modify the dissolution reaction) has been also investigated.
\end{abstract}

\section{INTRODUCTION:}

Since a few years, in-situ Scanning Tunneling Microscopy (STM) has been successfully used to study the structure of electrochemical interfaces. atomic resolution has been however only recently achieved with single crystals of noble metals [1]: The structure of UPD layers of various metals on Au and Pt, the reconstruction of bare surfaces and the arrangement of layers of adsorbates could indeed be imaged at an atomic scale.

Semiconductor surfaces in contact with electrolytes have also been investigated with the STM [2-8]. Atomic resolution appears much more difficult to obtain in-situ, particularly with reactive semiconductors such as GaAs or Si. STM imaging of the semiconductor-electrolyte contact has other limitations with respect to tunneling conditions. Monatomic steps were seen, two years ago, on silicon covered by $\mathrm{H}_{2} \mathrm{SO}_{4}$ [9] and in the $\mathrm{NH}_{4} \mathrm{~F}$ etch bath [10]. This is only last year that atomic resolution has been achieved on this material in acidic $\mathrm{HF}$ [11], in $\mathrm{H}_{2} \mathrm{SO}_{4}$ [12] and in $\mathrm{NaOH}$ solutions [13-14]. The latter studies is the only one to report real time imaging of the etching of silicon.

The etching of $\mathrm{Si}$ in alkaline solutions is very orientation-dependent [15], a property which finds many applications in industry. Some of our STM findings are recalled in this paper which further presents new results concerning the intluence of some species added in solution.

\section{in-situ STM IMAGING OF SEMICONDUCTOR ELECTRODES:}

Figure 1 compares STM imaging of semiconductors in the UHV and in the electrolytic environment. In the first situation, the tunneling junction is polarized so as to locate the tip Fermi level either above the conduction band or below the valence band edge (Fig. 1, left). This way empty and filled states are respectively imaged, which explains the bias dependent topography of STM images of semiconductor surfaces in the UHV (empty and filled states are indeed spatially localized on different atoms). Electron tunneling and therefore imaging is impossible if the tip Fermi level lies in the band gap (the tip crashes on the surface). UHV tunneling junctions are generally polarized by $\pm 2 \mathrm{~V}$ to image semiconductors.

In the case of the semiconductor-electrolyte (SC-EL) contact the tunneling junction can be decomposed into two interfaces, biased independently against a reference of potential if a 4 electrode configuration is implemented. The SC-EL $\left(U_{S}\right)$ contact behaves like a diode and the interface tip-solution $\left(U_{T}\right)$ is a 
metal microelectrode. Since the potential $U_{T}$ must be adjusted so as to minimize the faradaic process at the tip extremity, the energy diagram of the junction is generally that of Fig. 1 (right) with the tip Fermi level ( $\mathrm{U}_{\mathrm{T}}$ ) lying in the middle of the band gap. According to the UHV situation imaging should not be possible. Fortunately the tip can be nevertheless maintained stable above the surface by applying a proper bias $U_{S}$ to the sample to provide the necessary electrons to sustain the preset value of the tunneling current. With a ntype specimen it is necessary to decrease the inner potential barrier for electrons (i. e. to reduce the band bending by applying a cathodic polarization). Electrons tunnel therefore from the conduction band edge into the empty states of the tip. The consequence of Fig. 1 is that the range of potentials available is narrow for in-situ imaging of the SC-EL interface. These restrictions must be kept in mind but can be overcome with a special procedure as it was demonstrated elsewhere [14].

Fig.1: Energy diagram of the tunneling junction and typical $i-V$ curves of a n-type semiconductor electrode (SC) and tip. Top left: UHV situation and top right: Electrolytic environment. $\mathrm{U}_{\mathrm{S}}$
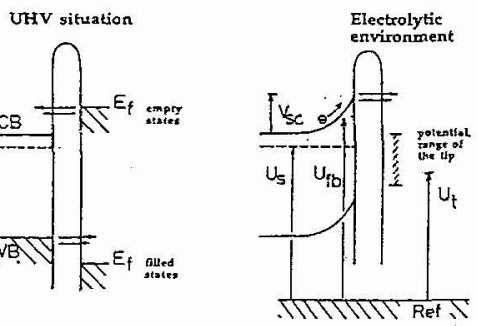
and $\mathrm{U}_{\mathrm{T}}$ are the sample and tip potentials quoted against a reference in solution.

\section{RESULTS:}

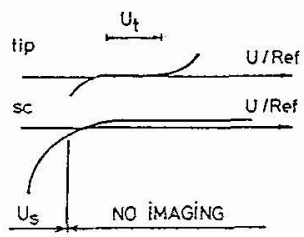

Figures. 2-3 present two sequences of STM images (top views) recorded in-situ on $\mathrm{Si}(111)$ when its contacts a solution of $2 \mathrm{M} \mathrm{NaOH}$. Heights are decreasing from white to black. The tunneling current
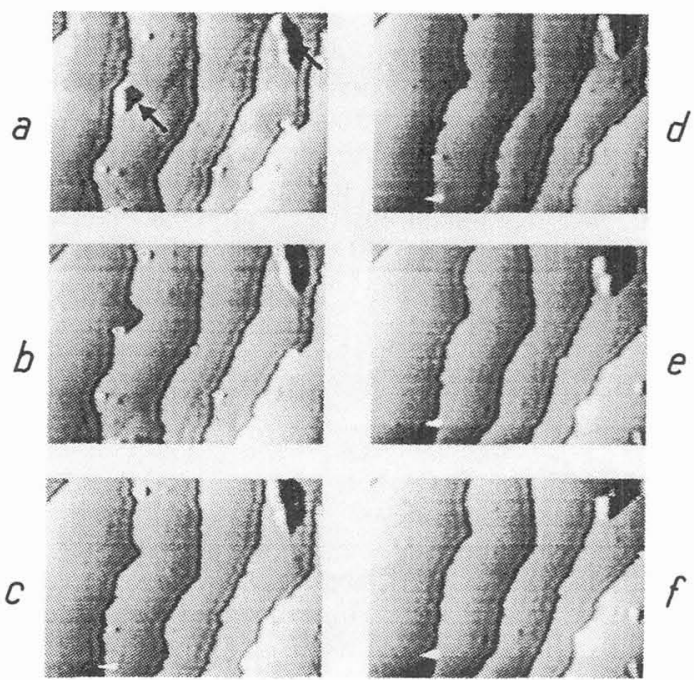

Figure 2: Sequence of STM images showing the evolution of step edges on an $\mathrm{n}-\mathrm{Si}(1,11)$ surface in contact with $2 \mathrm{M}$ $\mathrm{NaOH}$. The $\left(1470 \times 935 \ddot{A}^{2}\right)$ images $(a-f)$ have been recorded in $45 \mathrm{sec}$. The hydrogen current is $150 \mu \mathrm{A} / \mathrm{cm}^{2}$.
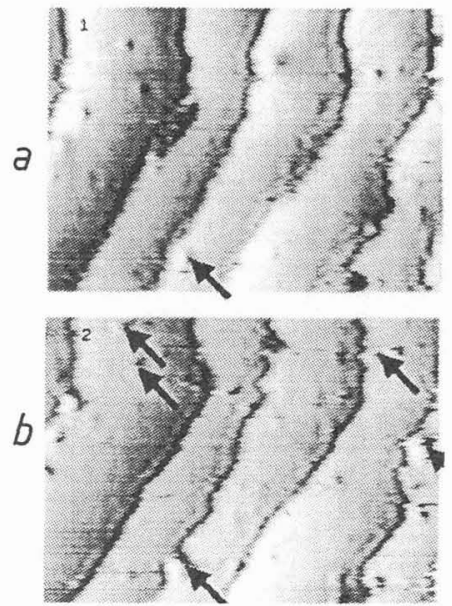

Figure 3: Same as Fig. 2 for a weaker hydrogen evolution rate $\left(45 \mu \mathrm{A} / \mathrm{cm}^{2}\right)$. 
is $0.2 \mathrm{nA}$ and images are recorded in $45 \mathrm{~s}$. The cathodic current (hydrogen evolution) on Si was 150 and $50 \mu \mathrm{A} / \mathrm{cm}^{2}$, respectively in Figs. 2 and 3 . In Fig. 2 the surface is initially composed of smooth terraces, separated by monoatomic steps ( $3.1 \mathrm{~A}$ high), which are descending from right to left. A close inspection of images shows that there is a slow lateral motion of terrace edges with time, which is not due to thermal drift, but to a completely anisotropic etching of $\mathrm{Si}$ at this bias. A pre-existing etch pit disappears between images (a) and (c) but no pit has nucleated. Reducing the hydrogen current, as in Fig. 3, accelerates the flow of steps and few new etch pits (3.1 A deep) appear. The resolution of images in this second sequence is not as good as in Fig. 2 because the situation corresponds to the limit of stability of the tunneling junction (see previous section). The surface is also more reactive. Recording more than two images was difficult at this bias. Approaching further the rest potential drastically increases the etch pit formation and there density reaches values of $10^{11}$ pits $/ \mathrm{cm}^{2}$. Importantly, pits are always $3.1 \AA$ deep.

Addition of a small quantity of surfactant such as Triton ${ }^{\circledR}(2$ drops in $200 \mathrm{cc}$ of $2 \mathrm{M} \mathrm{NaOH}$ solution) modifies significantly the foregoing observations. Fig. 4 shows a sequence of STM images. Terraces are going downward from left to right and images are recorded every $45 \mathrm{~s}$. For a cathodic current similar to that in Fig. 3, the formation of etch pit on the top of terraces is particularly slowed down. The motion of terrace edges is accordingly much slower.

Fig. 4: Same as Fig. 3 but Triton has been added into solution. The hydrogen current is $45 \mu \mathrm{A} / \mathrm{cm}^{2}$. Frames are $1400 \times 1400 \mathrm{~A}^{2}$.
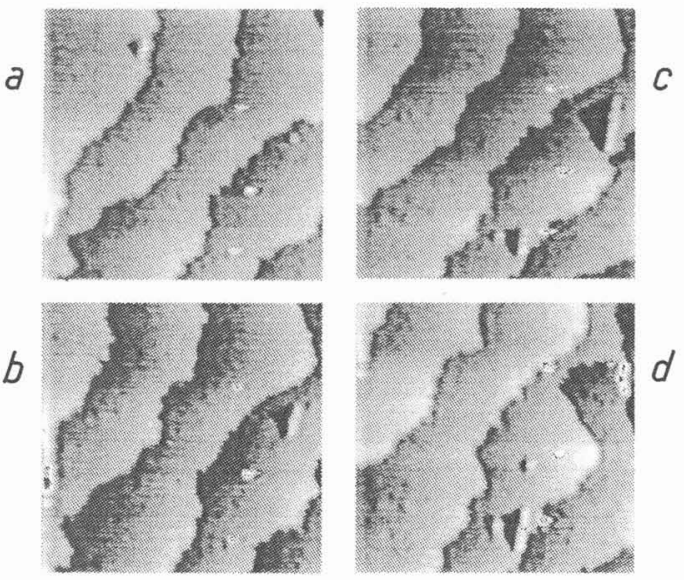

Though the organic molecules influence the etching reaction, Fig. 5 shows that the atomic structure of the Si surface can still be imaged, which suggests that molecules are not very strongly adsorbed on $\mathrm{Si}$ or that the tip exercises too strong interactions and push them on the surface. The ideal hexagonal (1x 1 ) atomic structure with an inter atomic distance of $3.8 \mathrm{~A}$ is characteristic of a surface of $\mathrm{Si}(111)$ saturated by hydrogen atoms. The corrugation is ca $0.2 \mathrm{~A}$ in this image. The same atomic arrangement is observed in $\mathrm{NaOH}$ [13-14] and in the UHV on HF treated surfaces [16]. The H termination of the surface in alkaline solution has been confirmed by ex-situ IR spectroscopy [17]

Fig. 5: Atomically resolved in-situ STM image of $\mathrm{n}-\mathrm{Si}(111)$ in $2 \mathrm{M} \mathrm{NaOH}$ in presence of Triton. The frame is $71 \times 21 \ddot{A}$.

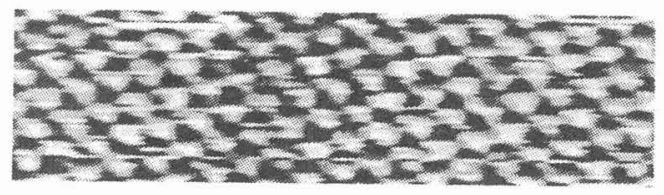

Figure 6 presents a sequence of in-situ STM images recorded in a solution containing sulphur and polysulfur species. There is again a strong influence of added species. For a cathodic current comparable to that of Fig. 3, no etch pit has nucleated, despite the much longer time between images ( $4 \mathrm{~min}$ ). The etch rate decreases by one order of magnitude which is more pronounced than in the case of Triton®. The process becomes again completely anisotropic. 
Fig. 6: Same as Fig. 2 in a $10^{-2} \mathrm{M}$ polysulfur solution for a hydrogen currents of $45 \mu \mathrm{A} / \mathrm{cm}^{2}$. Time between images is 4 min. Frames are $1300 \times 1300 \mathrm{~A}$.

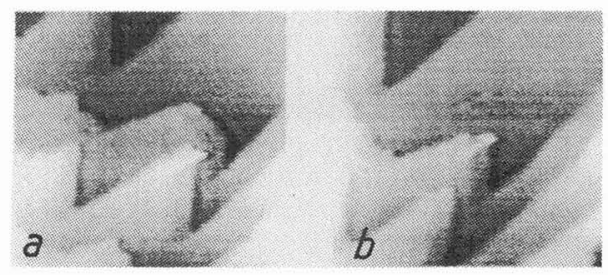

The reasons for the influence of polysulfur species are seen in Fig. 7. In Fig. 7a, terraces are going downward from left to right. In contrast to the series of Fig. 6, terraces do not look atomically flat and present depressions indicated with arrows. Depressed areas are about $1.45 \AA$ lower than the topmost layer which suggests the existence of a thin $1.45 \AA$ A thick overlayer on the Si surface. Between two terraces, steps are still 3.1 A high. The overlayer is probably due to about one monolayer of adsorbed $\mathrm{S}$ species as it can be seen in Fig. 7 $\mathrm{b}$. The atomic structure of the $\mathrm{S}$ layer is hexagonal as for Si. Since the $\mathrm{S}-\mathrm{S}$ distance is $\sim 3.3 \AA$ against $3.8 \ddot{\mathrm{A}}$ for $\mathrm{Si}-\mathrm{Si}$, and within the accuracy of lateral measurements with the STM the $S$ layer presents a $(6 \times 6)$ commensurable superstructure with the $(1 \times 1)-S i(111)$ surface. This structure is in further accordance with the long range undulation $(\sim 30 \AA)$ observed in the image.

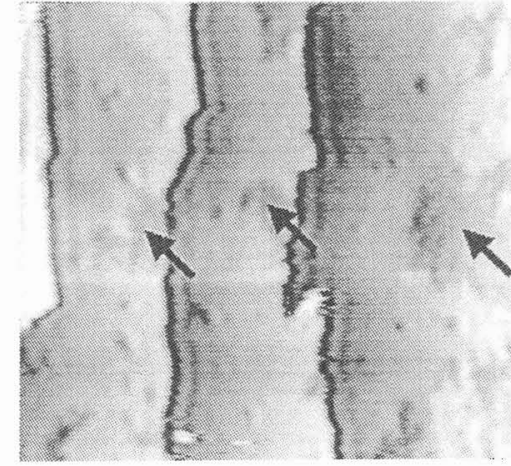

a

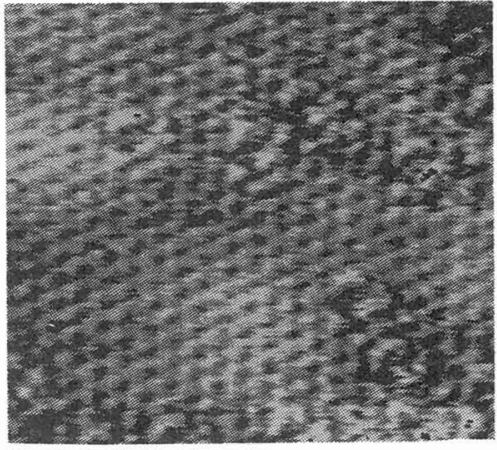

$b$

Fig. 7: Surface of $\mathrm{Si}(111)$ in a $10^{-2} \mathrm{M} S$ solution (a) $1424 \times 1420 \mathrm{~A}$ image. The $\mathrm{S}$ layer is incomplete et let appear holes on terraces (1.45 A deep). (b) Atomic structure of the layer $(64 \times 60 \AA$ ) $)$.

\section{DISCUSSION:}

Within the electrochemical conditions used in Figs. 2-3 the etching of Si(111) is a layer by layer etching process in $\mathrm{NaOH}$ which becomes a real step flow mechanism (i. e. terrace edges are exclusively etched) after addition of organic adsorbing species (Fig. 4). The local etch rate $\mathrm{R}$ has been evaluated from the displacement of the terrace edges as in Refs. [13-14] where it was shown that they were consistent with macroscopic measurements, as derived from loss material determinations. The expression used to calculate the etch rate is $R=(\Delta S / S) h / \Delta t$, with $\Delta S$ the area of terraces removed during the time $\Delta t$, $h=3.14 \AA$ the step height and $S$ the area of the surface under observation. Fig. 8 compares the variations of $\mathrm{R}$ against the cathodic current measured on $\mathrm{Si}(111)$ in different solutions. Since the etching of $\mathrm{n}-\mathrm{Si}$ is stopped by the evolution of $\mathrm{H}_{2}$ at cathodic bias [13-14], the parameter relevant to compare the effect of additives is the cathodic current rather than the applied potential (shifts of the band edges of Si are expected from $\mathrm{i}-\mathrm{V}$ curves). The decrease of the etch rate with addition of Triton $(\mathbb{B}$ or polysulfur is quantitatively determined and it is accompanied by a better anisotropy of the process. 
Fig. 8: Evolution of the etch rate $R$ of $\mathrm{Si}(111)$ as a function of the cathodic current in various solutions.

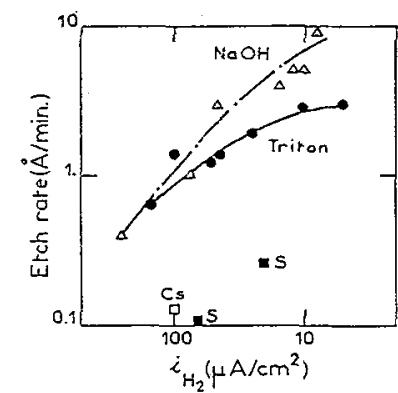

To analyze at an atomic level the effect of additives, the mechanism dissolution of $\mathrm{Si}$ in strong bases must be first considered [18]. It is mostly of chemical nature. At an atomic level, the reaction begins with the hydrolization of $\mathrm{Si}-\mathrm{H}$ bonds $\left(\mathrm{Si}-\mathrm{H}+\mathrm{H}_{2} \mathrm{O} \rightarrow \mathrm{Si}-\mathrm{OH}+\mathrm{H}_{2}\right)$ at a kink site. It continues with the chemical splitting of $\mathrm{Si}-\mathrm{Si}$ back bonds $\left(\mathrm{Si}-\mathrm{Si}+\mathrm{H}_{2} \mathrm{O} \rightarrow \mathrm{Si}-\mathrm{H}+\mathrm{Si}-\mathrm{OH}\right.$ ) in which the $\mathrm{H}$ and $\mathrm{OH}$ ligands respectively bind on the under-lying Si surface atom and on the Si atom which will finally enter in solution. Though representing $\mathrm{ca} 10 \%$ of the process at the rest potential, the electrochemical component of the reaction is important for the surface topography since the process is not as anisotropic as the chemical one. The electrochemical substitution $\mathrm{Si}-\mathrm{H}+\mathrm{OH} \rightarrow \mathrm{Si}-\mathrm{OH}+\mathrm{H}^{+}+2 \mathrm{e}^{-}$is indeed much less orientation dependent than the chemical substitution, since it involves the dissociation of $\mathrm{Si}-\mathrm{H}$ bonds as initial step. Steric hindrance is therefore less critical than for the chemical substitution where $\mathrm{H}_{2} \mathrm{O}$ must come in close contact with Si-H bonds.

Within this description, adsorption of additives must compete with adsorption of water molecules which hinders the hydrolization stage of $\mathrm{Si}-\mathrm{H}$ bond at terrace edges, where chemical dissolution predominantly occurs (Figs. 2-4) [18]. The quasi absence of etch pits formation in Figs. 4 and 6 means that adsorption of Triton (though not evidenced) or $\mathrm{S}$ also takes place on terraces to hinder the dissociation of $\mathrm{Si}-\mathrm{H}$ bonds (this step is responsible for the nucleation of pits). Given the structure of Triton $(\mathrm{X}-100$ molecules (polyethylene glycol tert-octyphenyl ether adsorption probably corresponds to a substitution of a $\mathrm{H}$ surface atom by the entity $\mathrm{R}$-O to form a bond such as $\mathrm{R}-\mathrm{O}-\mathrm{Si}$, with $\mathrm{R}=\mathrm{C}\left(\mathrm{CH}_{3}\right)_{3} \mathrm{CH}_{2} \mathrm{C}\left(\mathrm{CH}_{3}\right)_{2}-\mathrm{C}_{6} \mathrm{H}_{4}-$ $\left(\mathrm{OCH}_{2} \mathrm{CH}_{2}\right)_{\mathrm{n}} \mathrm{O}, \mathrm{n}=9-10$. Despite the expected small density of adsorbed molecules on the surface (for steric reasons) the efficient protection obtained suggests that an array of such big molecules remote water molecule away from the surface [19]. In the case of S species, the protection really takes place at an atomic level as Fig. $7 b$ shows.

\section{REFERENCES:}

[1] For a review, see H. Siegenthaler, in "Scanning Tunneling Microscopy II", R. Wiesendanger and H-. J. Güntherodt Eds., Spriger Series in Surface Science, 28 (1992)

[2] R. Sonnenfeld, J. Schneir, B. Drake, P. K. Hansma and D. E. Aspnes, Appl. Phys. Lett., 50, 1742 (1987).

[3] K. Itaya and E. Tomita, Surf. Sci., 219, L515 (1989); Chem. Lett., 285 (1989).

[4] T. Thundat, L. A. Nagahara and S. M. Lindsay, J. Vac. Sci. Technol., A8, 539 (1990).

[5] E. Tomita, N. Matsuda and K. Itaya, J. Vac. Sci. Technol., A8, 534 (1990).

[6] M. Szklarczyk, A. Gonzalez-Martin, O. Velev, J. O'M. Bockris, Surf. Sci., 237, 305 (1990).

[7] K. Sakamaki, K. Hinokuma, K. Hashimoto and A. Fujishima, Surf. Sci. Lett., 237, L383 (1990).

[8] S. Eriksson, P. Carlsson, B. Holmström and K. Uosaki, J. Electroanal. Chem., 313, 121 (1991).

[9] R. Houbertz, U. Memmert and R. J. Behm, Appl. Phys. Lett., 58, 1027 (1991).

[10] P. Allongue, V. Kieling and H. Gerischer, Int. Conf. on STM, Interlaken (1991), Abs. 3H/115.

[11] K. Itaya, R. Sugawara, Y. Morita and H. Tokumuto, Appl. Phys. Lett., 60, 2534 (1992)

[12] S. L. Yan, Fu Ren F. Fan and A. J. Bard, J. Electrochem. Soc., 139, 2825 (1992)

[13] P. Allongue, H. Brune and H. Gerischer, Surf. Sci., 275, 414 (1992)

[14] P. Allongue, V. Kieling and H. Gerischer, J. Electrochem. Soc., Part I, in press

[15] D. L. Kendall, Ann. Rev. Mater Sci., 9, 373 (1979)

[16] H. E. Hessel, A. Feltz, M. Reiter, U. Memmert and R. J. Behm, Chem. Phys. Lett., 186, 275 (1991).

[17] F. Ozanam and J-. N. Chazalviel, unpublished results

[18] P. Allongue, V. Kieling and H. Gerischer, J. Electrochem. Soc., Part II, in press

[19] J-. N. Chazalviel, A. Venkateswara Rao and F. Ozanam, Proceedings of the Electrochemical Society Meeting, Vol 88-14, The Electrochem. Soc.,Pennington (1988) 